\title{
DE AFETOS ROMÂNTICOS A PERFORMANCES NEONATURALISTAS: UMA REFLEXÃO SOBRE PRÁTICAS HOMOAFETIVAS NA LITERATURA DE LÍNGUA PORTUGUESA
}

\begin{abstract}
Antonio de Pádua Dias da Silva ${ }^{1}$
Resumo: A proposta do artigo foi refletir sobre como autores da chamada literatura gay desenvolvem estratégias linguísticas de escrita que expõem e problematizam desejos, tensões e conflitos culturais da população Lgbtqi+. A discussão se centrou na dinâmica dos afetos românticos e da linguagem obscena para tornar visível e crível o universo homoafetivo. Cinco obras literárias foram tomadas como corpus de leitura, duas portuguesas, duas brasileiras e uma alemã. Defende-se que a linguagem erótica é pertinente à expressão da intimidade das relações de afeto e sexo entre os personagens ou protagonistas dos textos tomados para análise.
\end{abstract}

Palavras-Chave: Visibilidade homoafetiva. Linguagem obscena. Desejo gay. Ativismo acadêmico.

\section{FROM ROMANTIC AFFECTIONS TO NEONATURALIST PERFORMANCES: A REFLECTION ON HOMOAFFECTIVE PRACTICES IN PORTUGUESE LANGUAGE LITERATURE}

\begin{abstract}
The purpose of the article was to reflect on how authors of the called gay literature develop linguistic writing strategies that expose and problematize the desires, tensions and cultural conflicts of the Lgbtqi+ population. The discussion focused on the dynamics of romantic affections and obscene language to make the homoaffective universe visible and credible. Five literary works were taken as reading corpus, one German, two Portuguese and two Brazilian. It is argued that erotic language is relevant to the expression of the intimacy of relationships of affection and sex between the characters or protagonists of the texts taken for analysis.
\end{abstract}

Keywords: Homoaffective visibility. Obscene language. Gay desire. Academic activism.

${ }^{1}$ Professor de Teoria da Literatura na Universidade Estadual da Paraíba. E-mail: docpadua70@gmail.com 


\section{Introdução}

Apesar de atualmente haver em nossa sociedade uma espécie de agenda política conservadora (da cultura binária) - que caminha na contramão do que já se conquistou e consta como política de minorias ou para grupos politicamente vulneráveis ${ }^{2}-$, sabe-se que é uma verdade, ainda em fluxo, o fato de grupos de pessoas postos sob a suspeição de subcultura ou minoritários (ERIBON, 2016) buscarem marcar seus lugares no mundo, projetando-se como sujeitos de si, arrolados em teias sociais e culturais que privilegiam o binário como norma, mas resistindo, por dentro (da norma), para demarcarem um território prioritário para a sua existência.

Falo da população Lgbtqi+ e de demais grupos de indivíduos que, pela não possibilidade, ainda, de uma terminologia capaz de contemplar todos os outros modos de existências referentes às práticas culturais de desejos, afetos e vivências entre os iguais (trato especificamente dos não heterossexuais masculinos), inserem-se na sigla referida ou, quando pensados, é a partir dessa terminologia que recebem um tratamento cultural enquanto subjetividade construída como parâmetro para os indivíduos que necessitam recorrer a um modo de reconhecimento no que tange às sexualidades e gêneros dissidentes.

Na literatura de ficção, em língua portuguesa e alemã, autores conhecidos ou em fase de conhecimento por nichos leitores têm se debruçado sobre questões do narrar a si mesmos ou de narrar a condição de si e de outros com os quais se identificam através da criação de personagens cujas subjetividades e afetos são endereçados para os seus iguais. Trata-se de um modo de se dar a conhecer, de insistir na inscrição de um grupo de sujeitos com existência e subjetividade próprias no mundo, todavia com seu estilo de vida rechaçado por grupos majoritários de poder (político, cultural, religioso etc.).

\footnotetext{
2 A noção de vulnerabilidade aplicada às pessoas e/ou população Lgbtqi+ é extraída diretamente de estudos da cultura e do campo jurídico. Trabalho, aqui, à luz de Séguin (2002) e de Ferreira (2017). Tomo a denominação Lgbtqi+ como a mais corrente no contexto ativista e acadêmico por incorporar uma soma maior de representação de sujeitos. Estou ciente de que outras siglas existem para nomear seus sujeitos, a seu modo e de acordo com a agenda política defendida por cada grupo identitário.
} 
Nesse sentido, pretendo refletir sobre a necessidade de um ativismo acadêmico no âmbito da crítica literária para a manutenção de uma forte rede de sustentação da defesa da população Lgbtqi+, sobretudo quando as representações desse grupo surgem de modo variado, diverso, fragmentado nas ficções literárias. Assim, tomo como objeto de discussão modos de expressar afeto e sexo gays na cultura de língua portuguesa, a partir de um corpus composto por três livros de prosa e dois livros de poemas arrolados na chamada literatura gay (SILVA, 2019). Tratam-se de Canções e outros poemas (2008), de António Botto; Borboletas em cinza: salmos profanos (2008), de Zeilton Feitosa; A morte em Veneza (2015), de Thomas Mann; Cidade proibida (2007), de Eduardo Pitta e Sim, sou gay, e daí? Desabafos do gay Alice no País das Maravilhas (2012), de Valdeck de Jesus.

Esse ativismo diz respeito a uma constante reflexão sobre como se instaura uma dinâmica social para encampar ou rechaçar políticas sobre pessoas não binárias quanto a questões de gênero e sexo. Entendo que a literatura, por assim dizer, como tantas outras artes que se preocupam com a discussão dos movimentos políticos e culturais da sociedade, têm papel importante na ampliação de respostas que possam se juntar a outras e tornem a vida de pessoas Lgbtqi+ mais acessíveis aos bens materiais, simbólicos, às políticas públicas, culturais, de saúde. Parto do pressuposto de que a literatura, ao colocar em evidência personagens, narradores e falas que explicitam os modos de existir gays enfrenta a política maior e redistribui, por dentro e por baixo (o que chamo de produtividade foucaultiana), ${ }^{3}$ aspectos dessa questão, tornando visível e viável um diálogo mais amplo, mais aberto, mais democrático sobre as sexualidades, desejos e subjetividades não heteronormativas.

\footnotetext{
3 Em Vigiar e punir (2001), Michel Foucault torna mais evidente a hipótese lançada em História da sexualidade I (1988), a de que o poder gera produtividade, negando a repressão pura como forma de o ver. Dentro de estruturas de poder, mesmo quando este intenta vigiar e punir, oportuniza-se a materialização produtiva e positiva de outros poderes, como foi o caso da visibilização e nomeação do homossexual (século XIX) enquanto espécie. Ou seja: apesar de todo um aparato social para negar esse sujeito, tornou-se existente, afirmando a sua identidade, passando a ser nomeado, visibilizado e incorporado ao social.
} 


\section{A linguagem obscena e neonaturalista como uma dinâmica de existência}

O campo literário, por se tratar de uma área de conhecimento restrita à cultura das Belles Lettres, da eloquência, mantida por um estrato social altamente letrado, intelectualizado, sempre vinculou, embora de modo tácito, a linguagem literária a um estilo limpo, moderado, distante de quaisquer marcas de uso da linguagem que pudessem associar, mesmo que minimamente, esse universo burguês ao contato com as linguagens comuns, do dia a dia, sobretudo, das pessoas que não circulavam afirmativamente nas representações literárias. A escrita criativa, apesar de hoje ser amplamente de domínio de todos, qualificou-se enquanto "alta literatura" (PERRONEMOISÉS, 1998) por se manter distante de vestígios menores de encenação de estórias que não estivessem relacionadas ao protagonismo elitista, burguês.

A chamada literatura gayimpulsiona seu vetor linguístico e crítico, no âmbito ficcional, quando formula internamente ao texto ou na própria construção textual, vivências e experiências afetivo-sexual entre personagens através do uso de uma linguagem pouco afeita aos pudores desse grupo social burguês a que inicialmente a prosa e a poesia literárias se destinavam, isso porque era desse mesmo estrato social de onde saíam os grandes nomes da arte do fingimento, da imaginação, invenção ou ficção literárias. Longe de assumir uma feição crítica no sentido de tornar menor e pejorativa essa performance linguística, assumo a postura de que a encenação obscena e neonaturalista ${ }^{4}$ da linguagem comparece em textos da ficção como modo de tornar os enredos mais próximos daquilo que possa soar como "verdade" ou como realidade.

\footnotetext{
${ }^{4}$ A noção de obsceno é vista aqui, a partir de Machado (2005), como na linguagem representativa de um universo de experiência pautado nas relações interpessoais que exigem para si o uso do "palavrão", da gestualidade direta às partes genitais, aos atos sexuais praticados entre seres. Basicamente, refere-se ao uso do calão sexual e da intimidade. Por neonaturalista estou chamando a linguagem que se centra na descrição de cenas erotizadas entre personagens homoafetivos. A noção de neonaturalista resgata a versão naturalista da literatura que defendia essa descrição como um modo de representar personagens em flagras doentios ou fora de ordem. No caso dos textos analisados neste artigo, o neonaturalismo relaciona-se à ideia de tornar verídica a cena exibida com um alto grau de realismo, tangenciando a transgressão linguística por a linguagem utilizada nessas cenas se opor ao modelo limpo de encenação de afeto, desejo e sexo culturalmente aceitáveis.
} 
Quando discute questões de poder, de manutenção do status quoeste enquanto equilíbrio que se mantém pela manutenção quase restrita a regras solidamente construídas e em manutenção na sociedade - entende-se também que o poder, ao colocar em evidência fatos como a questão gay, longe de apenas rechaçar discursos, práticas e sujeitos, oportuniza a relevância social e cultural do fato. Quando quer vigiá-lo, é porque ele já adquiriu corpo, existência. A própria escrita literária do tema é prova dessa produtividade.

Foucault (1988) afirma que o poder não se constrói apenas em uma relação unilateral como já se convencionou falar. Ao estabelecer grupos de poder em locais da cultura e da sociedade, mesmo quando estes se colocam como rígidos em suas regras e normas de conduta, os que são assujeitados a essas regras (quem elabora estratégias de poder também se sujeita ao ordenamento geral, apesar de estar em posição privilegiada e de comando) formulam para si modos de resistir, de caminhar na contramão do poder central e hegemônico, possibilitando o acesso de outros centros de poder (HUTCHEON, 1988). A passividade não é a lógica da produtividade; pelo contrário, o filósofo aponta a produtividade de conhecimento e de reconhecimento de grupos menorizados quando estes assumem a sua condição e, apesar de estarem arrolados em uma condição social e cultural de menor valor, encontram utopias de saída para se manterem enquanto críticos dentro de um sistema majoritário.

É o que acontece com as escritas de autores da literatura gay. mesmo dentro de um regime opressor de produção e leitura literárias, que preveem uma unilateralidade criativa gestada a partir de pressupostos cleans, do ponto de vista da linguagem, escritores tomam para si a tarefa de sujar o campo literário, num gesto altamente politizado e de natureza cuir (adoto o termo queer aportuguesado por INÁCIO, 2018), como modo de enfrentamento do status quo, de fazer-se conhecer e ser reconhecido enquanto sujeitos que produzem cultura, que vivem em regimes republicanos (onde o Estado é 'coisa' pública) e democratas (o direito emana do povo ao cumprir o seu dever enquanto Estado) e não admitem passivamente terem a sua expressão, subjetividade e estilo de vida regrados por normas conservadoras e unilaterais que prescrevem para o campo do desejo e da felicidade unicamente a alternativa heterossexual de desejo, de ser e de estar no mundo, punindo 
(física e simbolicamente) os que se orientam contrários a essa visão e versão de mundo.

O uso da linguagem naturalista e obscena (MACHADO, 2005), aquela que referenda, de modo político, uma postura crítica acerca do baixo corporal (BAKTHIN, 1987), é apropriada por autores dessa literatura, que optam por construir um modo de falar desejante, tornando a palavra como um elemento pré-discursivo, na visão lacaniana (LACAN, 1985), ou seja, uma linguagem não totalmente vigiada ou controlada pelo discurso de poder. É o caso das escritas sobre homens que gostam de homens, como diria Inácio (2018), uma espécie de linguagem cuir centrada em uma "epistemologia do rabo" ou "poética do cu" (INÁCIO, 2018, p. 34). Isso porque elaborada a partir de zonas corporais vicejantes, demonizadas, listadas ao longo das temporalidades cristãs como “pedaços do mal”, “caminho da perdição", "territórios de desejo pecaminoso", dentre outras figurações linguísticas que tornavam o campo do desejo sexual minado para a subjetividade do sujeito, para o desejo e a felicidade deste que teve negada a sua "estrutura psíquica" de sujeito que se subjetiva e se sente feliz porque contrário ao modo ordenado social e culturalmente. A linguagem obscena, então, naturaliza-se por se tornar clichê no dia a dia das personagens que encontram na subversão a harmonia psíquica.

\section{De afetos romantizados e performances obscenas}

Inicialmente publicado em 1912, em alemão, com o título Der Tod in Venedig, em língua portuguesa $A$ morte em Veneza (2015), Thomas Mann com estilo burguês, elitista, clássico, aborda a temática gay (ou homoerótica ou lgbt, como queira o leitor) de maneira singela, romantizada. Mesmo falando de uma prática de afeto e/ou desejo contrária à versão social da heterossexualidade compulsória, a limpeza de sua linguagem não deixa de traduzir desejos homoeróticos que só perturbam o protagonista (Aschenbach) porque ele vive uma luta interna (consigo), agravada por fatores externos: as demais personagens e a sua esposa percebem o enamoramento dele pelo imaturo e adolescente Tadzio. O trecho que segue demonstra a afeição e afinidade erótica e sentimental do figurativamente erastes (Aschenbach) pelo seu eromenos (Tadzio): 
Era um grupo de adolescentes e quase adultos [...] três mocinhas, de quinze a dezessete anos, segundo parecia, e um garoto de cabeleira comprida, a aparentar uns catorze anos. Com alguma surpresa Aschenbach constatou a perfeita beleza desse rapazinho. O rosto pálido, fino, fechado, os cabelos ondulados cor de mel que o emolduravam, a boca meiga, o nariz reto, a expressão de suave e divina dignidade - tudo isso lembrava esculturas gregas dos melhores tempos (MANN, 2015, p. 34).

A relação de afeto e, quando permitida, sexo entre um homem mais velho (erastes) e um jovem (eromenos) em processo de iniciação para a vida adulta e intelectual, no modelo dado pela Grécia antiga (DOVER, 2007), é trazida à tona, reformulada e pintada para surtir o efeito local e intencional do autor dessa narrativa. Em uma sociedade conservadora como a alemã ou europeia do início do século XX, a discussão em torno da dicção homoerótica relacionada aos iguais não foi a escolhida pela crítica. Mesmo quando o leitor se depara com narrações e descrições como a transcrita nesse artigo, a crítica amaneirada da época e do autor só conseguiu enxergar no olhar homoerótico de Aschenbach por Tadzio uma postura estética que buscava o ideal de Beleza a partir de uma compleição harmoniosa do corpo juvenil (para muitos conservadores, o desejo latente e pulsante de Aschenbach poderia ser visto, noutra vertente, como um olhar pedófilo).

Se a crítica quis assim, pouco interfere no argumento aqui em construção. A linguagem está registrada. A relação pode ser lida e interpretada sem nenhuma mediação cultural que busque mascarar o discurso que subjaz ao texto. O importante da relação é perceber que um personagem masculino endereça uma forte e tensa carga de desejo, de emoção a um outro sujeito, a um igual, em uma sociedade representada que não interpreta afirmativamente as relações fora da equação binária do homem para a mulher, da heterossexualidade compulsória, no dizer de Rich (2010). Toda a descrição da personagem adolescente é saturada de um desejo que ilusoriamente parece estar sublimado para o aspecto filosófico da beleza. $\mathrm{Na}$ verdade, trata-se da admiração de uma beleza ainda não incorporada 
plenamente ao desejo do voyeur, ${ }^{5}$ porque se nega a encarar de maneira direta e objetiva o corpo de desejo. Tensões sociais e culturais da época, de alguma forma, justificam essa sublimação ou transfiguração do desejo erótico em sentimento estético.

Atente-se para o fato de que, se remotamente o escritor encontra um meio romântico de problematizar um desejo homoerótico que torna a relação sujeito e sociedade tensa, é porque trata-se de uma verdade não somente latente, mas existente, fazendo parte da dinâmica de vida social, do perfil psicológico das pessoas da época a que se refere. Não se invenciona uma relação dessa natureza pelo simples fato de pintar com cores imaginativas. Aborda-se em literatura temas e sujeitos conflitantes, em tensão, de modo que reflexões profundas possam ser construídas a partir do objeto representado. Se sairmos da Alemanha e formos a Portugal, encontraremos António Botto com o poema que segue:

Não. Beijemo-nos, apenas,

Nesta agonia da tarde.

Guarda -

Para outro momento,

Teu viril corpo trigueiro.

O meu desejo não arde

E a convivência contigo

Modificou-me-sou outro...

A névoa da noite cai.

Já mal distingo a cor fulva

Dos teus cabelos. - És lindo!

A morte

Devia ser

Uma vaga fantasia!

${ }^{5}$ Digo voyeur, neste caso, porque o protagonista elabora o seu desejo a partir do campo visual, querendo iludir o leitor de que se trata de um fetiche, negando a confissão, o toque, a busca pela materialização do desejo. Este fica contido no olhar-câmera que projeta o foco de visão no garoto Tadzio. 
Dá-me o teu braço: - não ponhas

Esse desmaio na voz.

Sim, beijemo-nos, apenas!,

- Que mais precisamos nós?

(BOTTO, 2008, p. 45)

A mirada do sujeito lírico para o seu objeto de desejo - o jovem a quem endereça seu sentimento de amor - é expressa em uma linguagem que, por ser comedida, romantizada, ilude o leitor levemente com a impressão de uma suposta sublimação. Mas o sublime da relação ou afeto em questão se dilui nas entrelinhas do poema, saturado de desejo, de diálogo ou de confissão ao outro, como um modo de, por se tratar de uma fala verbalizada em um tempo talvez propício para um relaxamento do corpo e do espírito (agonia da tarde), alude a encontros ou vivências com o corpo do outro (Guarda/Para outro momento, /Teu viril corpo trigueiro). O sujeito poético quer, neste momento, apenas beijar o outro do seu afeto, porque naquele momento (já modificado o seu sentimento, como confessa, talvez para não performar unicamente um agente sexual) o seu desejo não arde. Por isso espera que, ambos, embarquem no pedido: Beijemo-nos.

A leitura do poema de António Botto apenas subliminarmente sugere uma expressão de obscenidade (e naturalista), se for considerado o fator tempo, vez que a confissão de amores proibidos, especificamente homoafetivos, à época em que o poeta escreve seus poemas (décadas de 20-30 do século XIX) não era bem acolhida pelos nichos leitores, pela cultura geral portuguesa. Vale comentar que a linguagem de desejo (obscena e naturalista) de sua produção poética fez que o autor, por conta do ostracismo recebido em sua terra (Portugal), se radicasse no Brasil, onde viveu boa parte de sua vida e morreu. A romantização ou amenização do amor homoerótico do poema citado não o exime de, discursivamente, demonstrar caracteres obscenos e naturalistas, de descrição confessional do amor do sujeito lírico masculino por um jovem rapaz (o poema encontra-se na primeira parte do livro Canções, intitulada "Adolescente").

A lírica homoerótica, logo, não se configura, na chamada literatura gay, apenas por esse vetor romantizado, passional, deslumbrado, estético. Se é 
possível perceber e sentir nos textos dados, apesar da tentativa de sublimar a relação entre homens gays, ou do olhar de homens gays para outros homens pelos quais sentem e confessam desejos físicos, há quem os externe (os sentimentos, os afetos) de modo mais diretivo, racional. A linguagem do desejo, a naturalista, mesmo quando tangenciando o obsceno, se estabelece numa linha política de afeto e desejo emanada da visão profunda que o sujeito da fala tem sobre si, sobre sua subjetividade, sobre seu modo de ser no mundo, a partir das configurações internas de sua adesão ou negação às estruturas sociais e culturais dos gêneros binários, da sexualidade compulsória (heterossexual = gêneros macho e fêmea).

Distante apenas do ponto de vista da abordagem (mais naturalista), mas nem por isso menos romântico, Zeilton Feitosa (2008) constrói poemassalmos que buscam atingir o íntimo do sujeito pelo lado da fé-devoção e da carne, campos distintos e antagônicos do viver, se lidos na chave de leitura judaica e cristã radical. O autor opta por dar um tratamento ao sentimento homoerótico do ponto de vista da carne, do desejo para, com isso, deixar mais evidente para os leitores que a obscenidade presente nos poemas do livro em comento faz parte do desejo por iguais. Desejo, afeto e sexo são, na visão desse autor, parcelas de razões de viver do sujeito humano, mesmo quando toda uma tradição afirmou que esses pilares de sustentação da subjetividade do sujeito só fossem capazes de ser sentidos e endereçados para pessoas do sexogênero diferentes. Leia-se o poema:

39 Glorificação ao anjo de corpo tão delicado.

O anjo deita-se em minha cama cada noite; desnuda-se sem pressa, e se debruça sobre meu corpo nu; enquanto exercita seu humano amor, a sua condição angelical ele renega.

$2 \mathrm{O}$ anjo deita-se em minha cama cada noite; e me queima com o amoroso calor do halo que rebrilha na escuridão; feito o bico do beija-flor na flor, no corpo seu alento se embrenha.

$3 \mathrm{O}$ anjo deita-se em minha cama cada noite; e com o adocicado hálito dos seus beijos a sede estanca; e feito morno reflexo no meu corpo, a claridade de sua aura resplandece.

$4 \mathrm{O}$ anjo deita-se em minha cama cada noite; e com sua deleitosa água deliciosamente invade a sedenta alma; e na 
volúpia de mãos tão delicadas todo meu corpo se embriaga.

$5 \mathrm{O}$ anjo deita-se em minha cama cada noite; e geme apaixonadamente, fartando a minha sede com a água pelo seu gozo perfumada; e cansada de amor, sopita a copiosa alma.

Vê-se que o Salmo 39, com cinco dísticos, recebe um tratamento linguístico que opera entre a delicada romantização da relação entre o fiel (sujeito lírico) e o seu anjo (erotizado na clave do desejo) e a obscena figurativização do desejo emanado da fala do masculino (eu-lírico) que confessa o recebimento de amor e sexo do seu objeto de desejo também masculino (anjo). Observe-se que todos os versos se iniciam com o paralelismo sintático "O anjo deita-se em minha cama cada noite", deixando em suspeito o fato que a relação é contínua. Trata-se, então, de uma relação amorosa que envolve afeto e sexo. A seleção vocabular do sujeito lírico denuncia esse valor lírico-amoroso encorpado ao gesto homoerótico da relação: desnuda-se, se debruça sobre meu corpo nu, exercita seu humano amor, me queima com o amoroso calor, hálito dos seus beijos, invade a sedenta alma, geme apaixonadamente.

A perspectiva naturalista dessa linguagem incide exatamente no modo de expressar uma relação afetivo-amorosa entre iguais, pautada em uma prática cultural de relacionamento interpessoal ainda mal vista por parte da sociedade, a conservadora. Daí se falar em obscenidade, porque essa só vem quando valores culturais em uso são transgredidos, enfrentados. O gesto naturalista, então, se serve do obsceno para tratar a linguagem de desejo a mais próxima da materialização do que poderia ser a relação entre os sujeitos. E é essa naturalização que aproxima o desejo homoerótico de práticas culturais rechaçadas socialmente que denunciam, por outra perspectiva (a não produtiva, na visão foucaultiana, 1988 e 2001), a obscenidade como algo negativo; o naturalismo linguístico como indecoroso, indevido.

Vale dizer que esse modo de tratar a linguagem no texto, operando entre a romantização e a obscenidade naturalista, nada mais é do que um modo de resistir, por dentro, de implodir estruturas, valores, de falar da existência de si, mesmo na contramão do discurso legitimado como modelo de 
ser. Trata-se de um artifício linguístico para se ter a liberdade de expor a subjetividade homoafetiva politicamente favorável à dinâmica diversa, plural e não binária dos afetos, dos gêneros e das orientações sexuais em sociedade. Trazer à tona amores homoafetivos em linguagem "natural" é também um modo de se posicionar literariamente a favor de outros modos (que não sejam exclusivamente cleans) de uso da linguagem em favor da representação desejada. As pessoas Lgbtqi+ sentem a necessidade de se posicionarem no mundo como sujeitos. A linguagem é um meio e, muitas vezes, ela é o próprio sujeito que se revela, que luta, que ama, que constrói a si e o seu entorno.

Há autores que, mesmo abordando relacionamentos de afeto e sexo entre personagens homoafetivos, insinuam, no campo do desejo, a naturalização da descrição, da narração ou caracterização do sentimento entre os envolvidos. O nível de obscenidade torna o texto menor? Evidente que não, diante dos vários usos da linguagem a favor da construção de estórias e ficções. Mas o pensamento conservador sempre optou por valorar negativamente a literatura que se utilizou de uma linguagem outsider, fora de linha, desviante, tendente a um descritivismo de afeto e sexo "constrangedor", mesmo quando se trata de relacionamentos heterossexuais. Não cabe o desenvolvimento dessa discussão no artigo, mas a assepsia do corpo cristão tende a levar esse modelo de limpeza para a linguagem, como se quaisquer aspectos relacionados ao corpo sexuado fosse sujo (ponto de vista conservador de cristãos) e, logo, a sua representação deveria se pautar pela sublimação do desejo que se quisesse carnal, materializável.

A linguagem escorregadia ou oscilante entre uma formalidade clean e uma exibição de cenas carregadas de desejo, obscenidades e pulsão erótica encontra-se na prosa de Eduardo Pitta e Valdeck Almeida de Jesus. Do primeiro, leia-se um trecho de Cidade proibida(2007):

Foi justamente na cozinha que Martin o comeu. A mesa era larga, tinha boa altura e um tampo surpreendentemente macio. Não se lembra qual dos dois chupou primeiro o outro. Lembra-se da luz crua do sol, de ter arrancado as calças e os briefs de Rupert, obrigando-o a dobrar-se no tampo de pedra negra, ao mesmo tempo que com a mão aberta lhe apertava a garganta à medida que o penetrava. Nunca tinham fodido de pé. O orgasmo 
foi praticamente simultâneo, sem que Rupert tivesse necessidade de se tocar. Nessas ocasiões, Martim afrouxava a pressão dos dedos para melhor sentir estremecer o corpo do companheiro (PITTA, 2007, p. 33$34)$.

Conhecido no meio intelectual português como crítico literário e ficcionista, a literatura gay desse autor promove em sua formulação interna uma representação do universo elitista de homens que endereçam seus afetos e desejos para outros do mesmo sexo, ferindo, por assim dizer, à luz do valor cultural onde a obra é gestada (sociedade portuguesa), costumes culturais pela linguagem mimética. Pitta (2007) torna evidente o mundo íntimo dos homens gays da elite, tornando a leitura de seus contos e novelas um aprendizado da cultura que circula por lugares em que o "bom tom" é regra e, por isso, Cidade proibida se torna corpus de análise aqui por sair do foco do estilo e valor sociais do meio acadêmico e social português para se instalar, enquanto linguagem, nos entornos da linguagem suja, rechaçada e de menor prestígio. Mas o desprestígio, caso fosse a obra interpretada apenas nessa chave de leitura, a da obscenidade ou ao rés do chão, não impede o intelectual de dar vida ao relacionamento entre Martin e Rupert, protagonistas gays da narrativa em análise.

Observe-se que a descrição naturalista da cena de sexo entre os personagens é exibida com uma cruza de imagem, despindo-se do pudor moral para intentar uma representação mais natural e viva do modo como ocorre a espontaneidade do desejo entre pessoas do mesmo sexo, quando elas se colocam à disposição para viverem o desejo e o sexo entre si. Longe de mimetizar uma linguagem encarcerada em princípios cristãos e/ou morais, o autor opta por dar longevidade ao crível da cena (distante da verossimilhança, por assim dizer) na intenção de marcar a sua escrita com uma veia política de identidade de gênero e orientação sexual que destoa da norma abrangente e requerida para os sujeitos culturais do local.

É essa acepção de literatura que trago à tona. Uma escrita capaz de dominar o campo do desejo entre os iguais, mimetizando a linguagem para que as cenas de relacionamentos homoafetivos não sofram cortes, censuras e possam ser lidas natural e espontaneamente para conhecimento de todos 
aqueles que se interessam pela ficção em suas várias modalidades de linguagem. Vale dizer que a linguagem obscena, por alguns tratadas como pornográfica, soa muito mais viva e crível quando verbalizada em momentos adequados por personagens homoafetivos. A pessoa que lê essa literatura passa a ter uma consciência de que mesmo diante de um aprendizado sobre o estilo único e clean da literatura que se quer universal, outros modos de uso da linguagem fazem parte da criação literária, da estética da palavra, da escrita criativa.

A linguagem mais próxima do contexto comunicacional em que se colocam as personagens ou narradores que linguisticamente aderem ao modo de tornar o mais crível possível a interação entre personagens é um recurso bastante utilizado em toda a literatura gay. O último autor a ser discutido aqui, Valdeck de Jesus, carrega a linguagem de seu romance com essa vertente naturalista, em uma ficção um tanto memorialística no sentido de que o/a protagonista da obra parte de sua infância até tornar-se adulto e enveredar pelo universo homossexual. As fases da sua vida não narradas à luz do desejo gay que desponta na criança, toma corpo no adolescente e encontra razão de viver no adulto. Do mesmo modo como Eduardo Pitta, a prosa de Jesus torna tensa a narração/descrição da estória que é permeada pela obscenidade necessária à atuação do/a protagonista da narrativa. Veja-se um trecho do texto:

O ciclista tirou um imenso cacete moreno para fora e me pediu para mamar. Tive receio de que alguém passasse pela calçada e visse aquela cena, mas não pude resistir ao imenso pênis latejante, cujo canal uretral parecia uma boca dizendo "me chupa, por favor". Mamei o pau dele por vários minutos. Depois, ele pediu que eu baixasse meu short e virasse o traseiro para ele. Obedeci, e ele começou a me enrabar. Eu gemia de tesão, de dor, ao tempo em que olhava para todos os lados preocupado, com medo de que aparecesse alguém [o lance entre os dois se dá em um lugar vazio de pessoas numa praia]. Trepamos por mais de meia hora, e quando terminamos me limpei e saí rapidamente do local. Nunca mais encontrei "O Ciclista". Uma pena (JESUS, 2012, p. 73). 
$\mathrm{O}$ argumento do artigo talvez seja recuperado de modo mais enfático com a transcrição deste último trecho. O leitor acompanhou as primeiras citações, começando com uma leve descrição romantizada (Thomas Mann) da relação homoafetiva, passando por um tracejado verbal mais quente e desejoso (António Botto e Zeilton Feitosa), até tangenciar uma mimetização crível da relação gay entre personagens (Eduardo Pitta e Valdeck de Jesus). Em Valdeck de Jesus, conforme trecho dado, longe de romantizar um encontro entre homens que se desejam e se endereçam para os iguais, a linguagem denota uma realidade presente no corpo do romance com tamanha força de veracidade que a cena parece fazer parte do cotidiano e se passa diante do leitor.

Esse modo de investimento em linguagem para tornar a ficção o mais verossímil possível, como dizem os críticos literários (CABRAL, 2003), parte da semelhança para chegar à cena, ou seja, o crível da cena, neste sentido, se dá em razão não de uma imitação ou de uma contação de estória, mas de uma criação linguística capaz de fazer emanar com naturalidade uma linguagem em que as personagens que encenam o sexo gay são colocados para serem lidos/vistos como verdadeiros, porque a seleção linguística, a semântica da sintaxe narrativa permite isso, principalmente para quem circula pelo "meio homossexual".

Assim, não apenas a cena em si, mas a pulsão de desejo que plenifica a cena recortada é construída na base naturalista do verbo, sem gagueira linguística, incorporando ao léxico do narrador a espontaneidade do relato saturado de termos representativos do calão sexual dos que se encontram para entabular relações de sexo e de afeto. O trecho dado da narrativa de Jesus (2012) incide sobre uma potencial linguagem que implode o modo limpo de construir narrativas, porque que defende um ponto de vista mais próximo da realidade linguística de quem usa a linguagem para comunicar seus desejos, tensões, tesão, conflitos. Montar a cena do sexo entre "O Ciclista" e Alice no País das Maravilhas ou entre Martin e Rupert, nos termos do encontro, exigiria o não pudor e o espontâneo das palavras para se referir a cada zona do corpo que negocia o desejo para o gozo mútuo. Daí a obscenidade ou pornografia para alguns (SILVA, 2002) e a verve naturalista para aqueles como eu que defendo a linguagem espontânea do desejo como um ato político 
frente a toda uma produção literária canônica e julgadora das estórias que não seguem o template asséptico e conservador.

\section{Considerações finais}

Logo na introdução deste artigo falei do ativismo intelectual, quando das considerações acadêmicas sobre gênero, sexualidades, orientações sexuais, desejos. O leitor há de perceber que a afirmação, lá, não foi gratuita. Há uma razão de ser dessa linguagem que, modulada pelo estilo autoral, pela época, pelo círculo social em que transita o autor, deságua na caracterização de uma linguagem que não só explora os desejos dos personagens de modo vivo e crível como também sabota esse desejo, tornando o relato sobre o desejo e o sexo de personagens uma mera cena despolitizada, distante das questões que envolvem empoderamento gay, construção de si, defesa de seu estilo de vida.

Os autores abordados neste artigo, cada um a seu modo, enveredaram, todos, para a construção de uma consciência linguística tradutora do desejo homoerótico, traçando na pena fagulhas ardentes que, para muitos, impacta pela tensão envolvendo o espúrio e o legítimo, o sujo e o clean. A reflexão que faço me permite tratar os cinco autores como modalizadores linguísticos que se apropriam da consciência e domínio que têm sobre a língua(gem) e a utilizam a favor da narração de cenas entre personagens que performam ao longo das obras como atores reais que dão vida a todo o cenário em que estão inseridos. Faz parte dessa dinâmica a liberdade de ser como se vive na vida real, daí o naturalismo da cena, da performance da personagem.

Cada texto escrito demonstra um compromisso com a questão gay que, ao longo das décadas, foi colocada como sem importância, menor ou, no mais das vezes, invisibilizada. O uso da linguagem para tornar a cena romântica e/ou obscena é um forte recurso ou tendência na literatura gaydar mais relevância ao que já é: a existência de sujeitos não heterossexuais que só enfrentam o sistema compulsório da sexualidade hegemônica porque têm a sua subjetividade rechaçada social e culturalmente. 
DE AFETOS ROMÂNTICOS A PERFORMANCES NEONATURALISTAS: UMA REFLEXÂOO SOBRE PRÁTICAS HOMOAFETIVAS NA LITERATURA DE LINGUA PORTUGUESA

\section{Referências}

BAKTHIN, Mikhail. A cultura popular na Idade Média e no Renascimento. Trad. Yara Frateschi Vieira. São Paulo: Hucitec, 1987.

BOTTO, António. Canções e outros poemas. Vila Nova de Famalicão: Edições Quase, 2008.

CABRAL, João Pina. Semelhança e verossimilhança: horizontes da narrativa etnográfica, Revista Mana, v. 1, n. 9, p. 109-122, 2003. Disponível em: https://www.scielo.br/pdf/mana/v9n1/a06v09n1.pdf. Acessado em $07 \mathrm{de}$ março de 2020.

DOVER, Kenetth. A homossexualidade na Grécia antiga. Trad. Luiz Sérgio Krausz. São Paulo: Editora Nova Alexandria, 2007.

ERIBON, Didier. Reflexões sobre a questão gay. Trad. Procópio Abreu. Rio de Janeiro: Companhia de Freud, 2016.

FEITOSA, Zeilton. Borboletas em cinza - Salmos profanos. São Paulo: Scortecci, 2008.

FERREIRA, Dina Maria Martins (Org.). Estudos críticos da linguagem. Curitiba: Appris, 2017.

FOUCAULT, Michel. História da sexualidade, v. I, a vontade de saber. Trad. Maria Tereza Albuquerque. 13. ed. Rio de Janeiro: Edições Graal, 1988.

FOUCAULT, Michel. Vigiar e punir. nascimento da prisão. Trad. Raquel Ramalhete. Petrópolis: Vozes, 2001.

HUTCHEON, Linda. Poética do pós-modernismo. Trad. Ricardo Cruz. Rio de Janeiro: Imago, 1988.

INÁCIO, Emerson da Cruz. Algumas interseccionalidades e um texto cuir para chamar de "(M)EU": retratos da produção estética afrolusobrasileira, Via Atlântica, n. 33, 2018, p. 225-240. Disponível em: http://www.periodicos.usp. br/viaatlantica/article/view/146353/147118. Acesso em: 29 jun. 2020.

JESUS, Valdeck Almeida de. Sim, sou gay...e daí? Desabafos do gay Alice no País das Maravilhas. São Paulo: Chiado Editora, 2012.

LACAN, Jacques. O seminário, Livro 20. Mais ainda. Trad. M. D. Magno. Rio de Janeiro: Jorge Zahar Editor, 1985.

MACHADO, José Barbosa. O léxico obsceno em prosa medieval portuguesa. In: Estudos em homenagem ao professor doutor Mário Vilela. v. 1. Porto: 
Faculdade de Letras da Universidade do Porto, 2005, p. 377-386. Disponível em: https://ler.letras.up. pt/uploads/ficheiros/4574.pdf. Acesso em: 2 jul. 2020.

MANN, Thomas. A morte em Veneza. Trad. Herbert Caro e Márcio Luiz Frungillo. São Paulo: Companhia das Letras, 2015.

PERRONE-MOISÉS, Leyla. Altas literaturas. escolha e valor na obra crítica de escritores modernos. São Paulo: Companhia das Letras, 1998.

PITTA, Eduardo. Cidade proibida. Matosinhos: Quidnovi, 2007.

RICH, Adrienne. Heterossexualidade compulsória e existência lésbica, Trad. Carlos Guilherme do Vale, Bagoas, n. 5, 2010, p. 17-44. Disponível em: https://cchla.ufrn.br/bagoas/v04n05art01_rich.pdf. Acessado em 10 de fevereiro de 2020.

SÉGUIN, Elida. Minorias e grupos vulneráveis. uma abordagem jurídica. São Paulo: Editora Forense, 2002.

SILVA, Antonio de Pádua dias da. A literatura gay. In: Teoria literária: abordagens históricas e tendências contemporâneas. BONNICI, Thomas \& ZOLIN, Lúcia Osana (Org.). 4. ed. ampliada e revista. Maringá: EDUEM, 2019, p. 355-368.

SILVA, Paulo Bessa da. Linguagem obscena, Revista Eletrônica Correlatio, n. 2, 2002, p. 77-83. Disponível em: https://www.metodista.br/revistas/revistasmetodista/index.php/COR/article/view/1817/1801. Acesso em15 de abril de 2020 .

Recebido em 22 de julho de 2020.

Aceito em 30 de outubro de 2020. 